\title{
Resolution of Gelatinous Bone Marrow Transformation Following Hormone Replacement Therapy in a Patient with Primary Insufficiency of the Adrenal and Thyroid Glands
}

\author{
Yoshinari Obata ${ }^{1}$, Sachiko Tamba ${ }^{1}$, Yuya Yamada ${ }^{1}$, Mitsuaki Kyo ${ }^{1}$, Yasumitsu Takahi ${ }^{1}$, \\ Kenji Saisho ${ }^{1}$, Akiyuki Yamato ${ }^{2}$, Kenji Hattori ${ }^{2}$, Hidetoshi Ujiie ${ }^{3}$, Shigeki Fujita ${ }^{4}$, \\ Koji Yamamoto $^{1}$ and Yuji Matsuzawa ${ }^{1}$
}

\begin{abstract}
A 59-year-old man with recurrent oral cancer presented with severe pancytopenia, hyponatremia and hypoglycemia. Endocrine testing showed a partial primary adrenal insufficiency and primary hypothyroidism. The bone marrow biopsy showed a gelatinous transformation with hypocellularity and fat atrophy. His pancytopenia, hyponatremia and hypoglycemia resolved following treatment with corticosteroids and thyroid hormone replacement therapy. The follow-up bone marrow biopsy demonstrated a resolution of the gelatinous transformation. This case is a rare example of a patient with a primary insufficiency of the adrenal and thyroid glands that is associated with gelatinous bone marrow transformation (GMT). The GMT was resolved through the admimistration of corticosteroids and thyroid hormone replacement therapy.
\end{abstract}

Key words: gelatinous bone marrow transformation, adrenal insufficiency, hypothyroidism

(Intern Med 52: 1931-1936, 2013)

(DOI: 10.2169/internalmedicine.52.0081)

\section{Introduction}

Gelatinous bone marrow transformation (GMT) is a rare disorder of unknown pathogenesis that is characterized by fat cell atrophy, focal loss of hematopoietic cells and the deposition of extracellular gelatinous material which is composed of mucopolysaccharides and is rich in hyaluronic acid $(1,2)$. GMT is not a specific disease of the bone marrow, but it is instead associated with generalized severe illnesses (3). There are several reports of the associations between GMT and anorexia nervosa (4-6), malignancy $(7,8)$ and infectious diseases such as tuberculosis (9), human immunodeficiency virus (HIV) and acquired immune deficiency syndrome (AIDS) $(10,11)$. However, there have so far been few reports describing the associations between GMT and metabolic abnormalities. We herein present the first reported case of an association between GMT and a primary insufficiency of the adrenal and thyroid glands. This case was successfully treated with corticosteroids and thyroid hormone replacement therapy.

\section{Case Report}

A 59-year-old man was admitted to our hospital for treatment of his fourth recurrence of oral cancer. He was diagnosed with oropharyngeal, hypopharyngeal and esophageal cancers at 50 years of age, and underwent laryngopharyngectomy, total esophagectomy, right thyroidectomy, postoperative radiation therapy and chemotherapy with docetaxel. Three years later, at 53 years of age, he was diagnosed with his first recurrence of oral cancer, and underwent surgical resection. He had 3 subsequent recurrences of oral cancer within 6 years, and was treated with surgical resection or

${ }^{1}$ Department of Endocrinology and Metabolism, Sumitomo Hospital, Japan, ${ }^{2}$ Department of Otorhinolaryngology, Head and Neck Surgery, Sumitomo Hospital, Japan, ${ }^{3}$ Department of Hematology, Sumitomo Hospital, Japan and ${ }^{4}$ Department of Pathology, Sumitomo Hospital, Japan Received for publication January 8, 2013; Accepted for publication April 17, 2013

Correspondence to Dr. Yoshinari Obata, yoshinari0811@hotmail.co.jp 
Table 1. Laboratory Data on Admission

\begin{tabular}{|c|c|c|c|c|c|}
\hline$<$ Peripheral blood $>$ & & & AST & 51 & $\mathrm{IU} / \mathrm{L}$ \\
\hline WBC & 1,500 & $/ \mu \mathrm{L}$ & ALT & 24 & $\mathrm{IU} / \mathrm{L}$ \\
\hline Blast & 0.0 & $\%$ & ALP & 408 & $\mathrm{IU} / \mathrm{L}$ \\
\hline $\mathrm{Neu}$ & 56.0 & $\%$ & $\gamma-\mathrm{GT}$ & 77 & $\mathrm{IU} / \mathrm{L}$ \\
\hline Eosin & 4.0 & $\%$ & $\mathrm{ChE}$ & 122 & $\mathrm{IU} / \mathrm{L}$ \\
\hline Lym & 32.5 & $\%$ & $\mathrm{LDH}$ & 234 & $\mathrm{IU} / \mathrm{L}$ \\
\hline Mono & 7.5 & $\%$ & TP & 5.0 & $\mathrm{~g} / \mathrm{dL}$ \\
\hline $\mathrm{RBC}$ & $189 \times 10^{4}$ & $/ \mu \mathrm{L}$ & Alb & 3.0 & $\mathrm{~g} / \mathrm{dL}$ \\
\hline $\mathrm{Hb}$ & 6.7 & $\mathrm{~g} / \mathrm{dL}$ & T-Cho & 126 & $\mathrm{mg} / \mathrm{dL}$ \\
\hline $\mathrm{MCV}$ & 102.6 & $\mathrm{fL}$ & TG & 30 & $\mathrm{mg} / \mathrm{dL}$ \\
\hline Plt & $6.4 \times 10^{4}$ & $/ \mu \mathrm{L}$ & HDL-C & 77 & $\mathrm{mg} / \mathrm{dL}$ \\
\hline$<$ Biochemistry $>$ & & & FPG & 62 & $\mathrm{mg} / \mathrm{dL}$ \\
\hline $\mathrm{Na}$ & 119 & $\mathrm{mEq} / \mathrm{L}$ & HbAlc (NGSP) & 4.9 & $\%$ \\
\hline $\mathrm{K}$ & 4.7 & $\mathrm{mEq} / \mathrm{L}$ & Insulin & $<1.0$ & $\mu \mathrm{U} / \mathrm{mL}$ \\
\hline $\mathrm{Cl}$ & 88 & $\mathrm{mEq} / \mathrm{L}$ & CPR & 0.61 & $\mathrm{ng} / \mathrm{mL}$ \\
\hline $\mathrm{Ca}$ & 7.7 & $\mathrm{mg} / \mathrm{dL}$ & P-Osm & 240 & $\mathrm{mOsm} / \mathrm{kg}$ \\
\hline $\mathrm{P}$ & 3.7 & $\mathrm{mg} / \mathrm{dL}$ & $<$ Urinalysis $>$ & & \\
\hline UN & 9 & $\mathrm{mg} / \mathrm{dL}$ & U-Na & 118 & $\mathrm{mEq} / \mathrm{L}$ \\
\hline $\mathrm{Cr}$ & 0.43 & $\mathrm{mg} / \mathrm{dL}$ & $\mathrm{U}-\mathrm{Cr}$ & 110 & $\mathrm{mEq} / \mathrm{L}$ \\
\hline UA & 1.6 & $\mathrm{mg} / \mathrm{dL}$ & U-Osm & 301 & $\mathrm{mOsm} / \mathrm{kg}$ \\
\hline \multicolumn{6}{|c|}{$\begin{array}{l}\text { WBC: white blood cell count, Neu: neutrophils, Eosin: eosinophils, Lym: lymphocytes, Mono: } \\
\text { monocytes, RBC: red blood cell count, Hb: hemoglobin, MCV: mean corpuscular volume, Plt: } \\
\text { platelet count, Na: sodium, K: potassium, Cl: chloride, Ca: calcium, P: phosphorus, UN: blood } \\
\text { urea nitrogen, Cr: creatinine, UA: uric acid, AST: aspartate aminotransferase, ALT: alanine } \\
\text { aminotransferase, ALP: alkaline phosphatase, } \gamma \text {-GT: } \gamma \text {-glutamyl transferase, ChE: cholinesterase, } \\
\text { LDH: lactate dehydrogenase, TP: total protein, Alb: albumin, T-Cho: total cholesterol, TG: } \\
\text { triglycerides, HDL-C: high-density lipoprotein cholesterol, FPG: fasting plasma glucose, } \\
\text { HbAlc: hemoglobin A1c, NGSP: national glycohemoglobin standardization program, CPR: } \\
\text { C-peptide reactivity, P-Osm: plasma osmolarity, U-Na: urinary sodium, U-Cr: urinary creatinine, } \\
\text { U-Osm: urinary osmolarity }\end{array}$} \\
\hline
\end{tabular}

chemotherapy each time. He had been diagnosed with epilepsy at age 35 . He had tried several antiepileptic drugs, but most were discontinued due to either adverse effects or limited effectiveness. He was eventually treated with phenytoin at a dosage of $180 \mathrm{mg} / \mathrm{day}$ starting at age 49 . He was diagnosed with primary hypothyroidism at 58 years of age, and was treated with levothyroxine sodium at a dosage of $75 \mu \mathrm{g} /$ day.

Upon this admission, his height was $156.3 \mathrm{~cm}$, his weight was $35.2 \mathrm{~kg}$ and his body mass index (BMI) was $14.4 \mathrm{~kg}$ / $\mathrm{m}^{2}$. He was alert and oriented but he had a flat affect and complained of fatigue. His blood pressure was 94/68 $\mathrm{mmHg}$, his pulse rate was $74 \mathrm{bpm}$ and his body temperature was $35.3^{\circ} \mathrm{C}$. No abnormal pigmentation of the skin or mucosa was observed. He had only scant pubic and auxiliary hair growth. He had recurrent cancer in the left floor of his mouth, and his left cervical lymph nodes were enlarged. He had a permanent tracheostomy in place as a result of his previous surgery, therefore, his thyroid gland was not palpable. There was no peripheral edema. The routine laboratory results are shown in Table 1. He had severe pancytopenia with a white blood cell count of $1,500 / \mu \mathrm{L}$, a hemoglobin level of $6.7 \mathrm{~g} / \mathrm{dL}$ and a platelet count of $6.4 \times 10^{4} / \mu \mathrm{L}$. He also had severe hyponatremia, as indicated by a serum sodium concentration of $119 \mathrm{mEq} / \mathrm{L}$, and hypoglycemia, as indicated by a fasting plasma glucose level of $62 \mathrm{mg} / \mathrm{dL}$. He was previously unaware of his hypoglycemia. His low levels of albumin, cholinesterase and total cholesterol suggested a poor nutritional status. Additional laboratory data, including the basal endocrinological data, are shown in Table 2. His serum cortisol and aldosterone levels were within normal limits, but his urinary excretion of free cortisol was decreased, his serum dehydroepiandrosterone-sulfate level was decreased and his plasma adrenocorticotropic hormone (ACTH) level was increased. His serum free triiodothyronine and free thyroxine levels were decreased, and his serum thyroid stimulating hormone level was increased despite his replacement therapy of levothyroxine sodium at a dosage of $75 \mu \mathrm{g} /$ day. He was negative for the anti-thyroglobulin antibody, the anti-thyroid peroxidase antibody and the antiadrenocortical antibody. There was no evidence of an infection with HIV, tuberculosis, fungi or cytomegalovirus. His serum cortisol level showed a partial response to the intravenous administration of $250 \mu \mathrm{g}$ of ACTH (Table 3). His plasma ACTH level responded normally to an intravenous administration of $100 \mu \mathrm{g}$ of a corticotrophin-releasing hormone (Table 3). His urinary excretion of free cortisol adequately increased after the intramuscular administration of long-acting ACTH at a dosage of $1 \mathrm{mg} /$ day for 4 days (Table 3). Abdominal computed tomography showed no morphological abnormalities of the adrenal glands. Contrast enhanced magnetic resonance imaging of the pituitary gland was normal. The thyroid gland could not be detected with ultrasonography because of his previous surgeries. Based on these results, he was diagnosed with a partial idiopathic primary adrenal insufficiency and primary hypothyroidism, the 
Table 2. Other Laboratory Data Including Baseline Endocrinological Data

\begin{tabular}{lrllrl}
\hline$<$ Endocrinological examination $>$ & Adrenaline & $<5 \mathrm{pg} / \mathrm{mL}$ \\
ACTH & 82.1 & $\mathrm{pg} / \mathrm{mL}$ & Noradrenaline & $778 \mathrm{pg} / \mathrm{mL}$ \\
Cortisol & 8.6 & $\mu \mathrm{g} / \mathrm{dL}$ & Dopamin & $21 \mathrm{pg} / \mathrm{mL}$ \\
TSH & 86.37 & $\mu \mathrm{IU} / \mathrm{mL}$ & $<$ Autoantibody $>$ & & \\
FT3 & 1.2 & $\mathrm{pg} / \mathrm{mL}$ & TgAb & $<10.0 \mathrm{IU} / \mathrm{mL}$ \\
FT4 & 0.6 & $\mathrm{ng} / \mathrm{dL}$ & TPOAb & $<5.0 \mathrm{IU} / \mathrm{mL}$ \\
GH & 2.94 & $\mathrm{ng} / \mathrm{mL}$ & Insulin Ab & $<0.4 \mathrm{U} / \mathrm{mL}$ \\
IGF-1 & 19 & $\mathrm{ng} / \mathrm{mL}$ & Adrenocortical Ab & negative & \\
PRL & 19.33 & $\mathrm{ng} / \mathrm{mL}$ & $<$ Infectious examination $>$ & \\
LH & 6.20 & $\mathrm{mIU} / \mathrm{mL}$ & Beta D glucan & $8.3 \mathrm{pg} / \mathrm{mL}$ \\
FSH & 20.82 & $\mathrm{mIU} / \mathrm{mL}$ & C7-HRP & negative & \\
DHEA-S & $<2$ & $\mu \mathrm{g} / \mathrm{dL}$ & QuantiFERON & negative & \\
PRA & 0.3 & $\mathrm{ng} / \mathrm{mL} / \mathrm{h}$ & PPD test & negative & \\
Aldosterone & 73.1 & $\mathrm{pg} / \mathrm{mL}$ & HIV antibody & negative & \\
ACE & 8.1 & $\mathrm{U} / \mathrm{L}$ & $<$ Urinary excretion $>$ & & \\
Testosterone & 2.10 & $\mathrm{ng} / \mathrm{dL}$ & Free cortisol & $21.7 \mathrm{\mu g} / \mathrm{day}$ \\
\hline ACTH: adr & & & & \\
\hline
\end{tabular}

ACTH: adrenocorticotropic hormone, TSH: thyroid stimulating hormone, FT3: free triiodothyronine, FT4: free thyroxine, GH: growth hormone, IGF-1: insulin-like growth factor-1, PRL: prolactin, LH: luteinizing hormone, FSH: follicle stimulating hormone, DHEA-S: dehydroepiandrosterone-sulfate, PRA: plasma renin activity, ACE: angiotensin converting enzyme, TgAb: anti-thyroglobulin antibody, TPOAb: anti-thyroid peroxidase antibody, Insulin $\mathrm{Ab}$ : anti-insulin antibody, Adrenocortical Ab: anti-adrenocortical antibody, PPD test: Purified Protein Derivative test, HIV: human immunodeficiency virus

Table 3. Tests for Pituitary-Adrenal Axis Function

\begin{tabular}{|c|c|c|c|c|c|c|}
\hline \multicolumn{7}{|c|}{ Intravenous $250 \mu \mathrm{g}$ of ACTH loading test } \\
\hline & 0 & 30 & 60 & $(\min )$ & & \\
\hline Cortisol & 12.0 & 16.2 & 17.3 & $(\mu \mathrm{g} / \mathrm{dL})$ & & \\
\hline Aldosterone & 18.8 & 36.0 & 26.5 & $(\mathrm{ng} / \mathrm{dL})$ & & \\
\hline \multicolumn{7}{|c|}{ Intravenous $100 \mu \mathrm{g}$ of corticotrophin releasing hormone loading test } \\
\hline & 0 & 30 & 60 & 90 & 120 & $(\min )$ \\
\hline ACTH & 121 & 209 & 271 & 196 & 154 & $(\mathrm{pg} / \mathrm{mL})$ \\
\hline Cortisol & 10.9 & 11.1 & 13.1 & 13.4 & 12.5 & $(\mu \mathrm{g} / \mathrm{dL})$ \\
\hline \multicolumn{7}{|c|}{ Intramuscular $1 \mathrm{mg}$ of long-acting ACTH loading test } \\
\hline & 0 & 1 & 2 & 3 & 4 & (day) \\
\hline U-Cortisol & 50.7 & 518 & 1,160 & 2,445 & 3,312 & ( $\mu \mathrm{g} /$ day) \\
\hline
\end{tabular}

latter of which could have been caused by the removal of his right thyroid and the subsequent postoperative irradiation. A dry tap bone marrow aspiration and biopsy from his iliac crest showed the gelatinous material that is associated with marrow hypoplasia and fat atrophy (Fig. 1). The gelatinous material accounted for approximately $70 \%$ of the bone marrow space.

We canceled the planned chemotherapy for his oral cancer and started hydrocortisone replacement therapy at a dosage of $10 \mathrm{mg} /$ day, which we gradually increased to $20 \mathrm{mg} /$ day. The time course of the changes in the laboratory values following his admission is shown in Fig. 2. Following the initiation of the hydrocortisone replacement therapy, his hyponatremia gradually improved and his hypoglycemia resolved. His pancytopenia also improved markedly. We then gradually increased his dosage of levothyroxine sodium to a dosage of $150 \mu \mathrm{g} /$ day in order to normalize his thyroid function. His hyponatremia and pancytopenia subsequently resolved completely. His face became more expressive and his fatigue resolved. His blood pressure increased to $110 / 70$
mmHg. He gained a little weight and his BMI increased to $15.8 \mathrm{~kg} / \mathrm{m}^{2}$. His hypoalbuminemia and hypocholesterolemia resolved, as indicated by an albumin level of $3.8 \mathrm{~g} / \mathrm{dL}$ and a cholesterol level of $168 \mathrm{mg} / \mathrm{dL}$, respectively. A follow-up bone marrow biopsy that was performed after 5 months of hormone replacement therapy revealed the presence of normocellular marrow without any gelatinous material (Fig. 3).

\section{Discussion}

GMT is characterized by focal hypoplasia of the fat and hematopoietic cells in the bone marrow and the accumulation of an extracellular gelatinous material that is mainly composed of hyaluronic acid $(1,2)$. GMT was first recognized in autopsy specimens of patients with a history of prolonged starvation and cachexia, and has also been termed "starvation marrow" or "fat atrophy" (12). GMT is not a specific disease of the bone marrow, but is found in some patients with severe illnesses (3). Several cases of GMT have been reported, but in most instances, the GMT was as- 


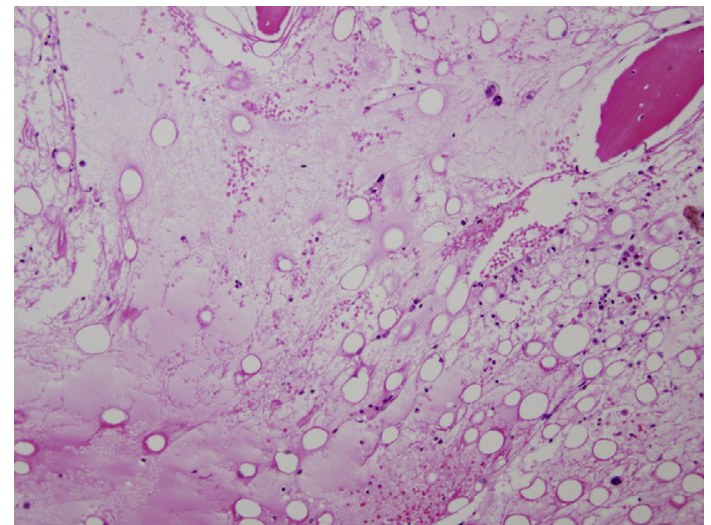

Figure 1. The bone marrow biopsy specimen showing severe hypoplasia, fat atrophy and the replacement of bone marrow by gelatinous material (Hematoxylin and Eosin staining $\times \mathbf{2 0}$ ).

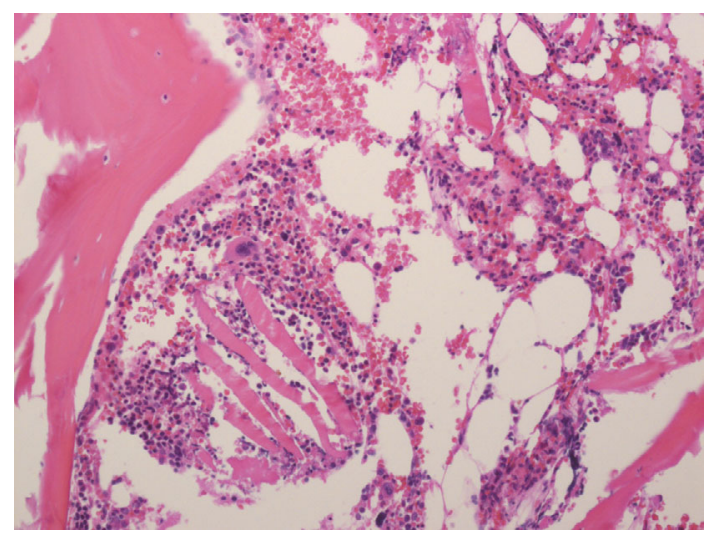

Figure 3. The bone marrow biopsy after 5 months of corticosteroids and thyroid hormone treatment (Hematoxylin and Eosin staining $\times 40$ ). By this time, the gelatinous material had disappeared.

sociated with anorexia nervosa (4-6), HIV or AIDS (10, 11). Bohm described 155 cases of GMT that were identified among 80,000 marrow biopsies (3). He reported that 37.5\% of the affected patients had tumors (including nonHodgkin's lymphoma and carcinoma), $16.8 \%$ were malnourished (due to causes such as alcoholism or anorexia nervosa), $11.8 \%$ had infectious diseases (such as AIDS or an acute febrile illness), $10.1 \%$ had maldigestion (due to stomach ulcers or previous gastrectomy) and $7.0 \%$ had congestive heart failure. Sen et al. reported the findings of 65 cases of GMT with a very similar spectrum of underlying diseases; most of these cases of GMT were associated with weight loss and chronic malnutrition (13). Hyaluronic acid has been suggested to replace the fat cells in the marrow that are used during a catabolic state, but the mechanisms leading to GMT are still unclear $(6,12)$. GMT may be reversible if the underlying disorder is treated, and the complete disappearance of GMT has been reported in patients that were treated for anorexia nervosa (6).

There have so far been very few reports of cases of GMT that are associated with metabolic disorders. Bohm reported

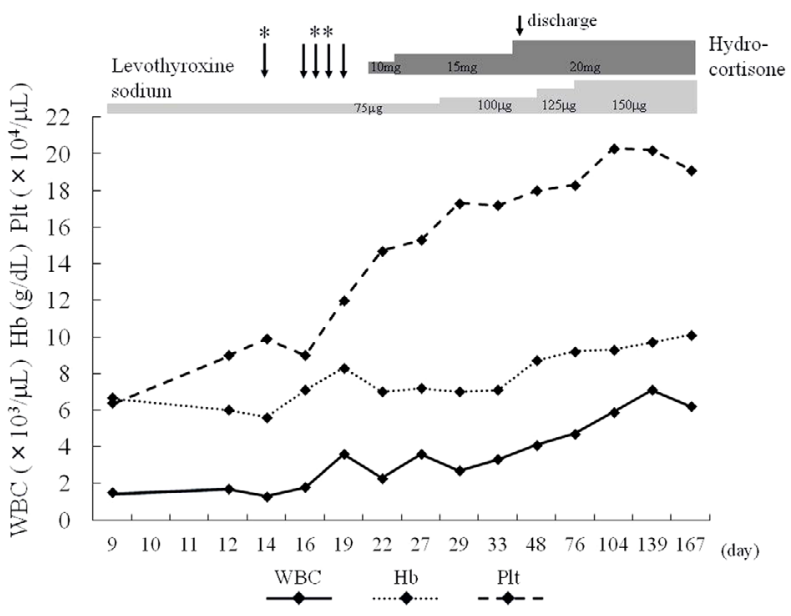

Figure 2. The time course of the changes in the laboratory values following admission. *Transfusion with 2 units of red blood cells. **A long-acting adrenocorticotropic hormone loading test over 4 days. Hb: hemoglobin, Plt: platelet count, WBC: white blood cell count

that $5.4 \%$ of the reviewed GMT cases were associated with metabolic disorders such as type 1 diabetes mellitus or hypothyroidism, but there were no clinical details provided, and the responses to the treatments were not reported (3). Only one case of GMT associated with hypothyroidism has been reported (14). To the best of our knowledge, GMT associated with an adrenal insufficiency has not previously been reported. In our patient, we believe that the GMT was caused by an adrenal insufficiency along with hypothyroidism because his pancytopenia clearly improved after the initiation of hydrocortisone replacement therapy, but before any improvements in his thyroid hormone levels were noted. This case, therefore, is a rare case of GMT associated with an adrenal insufficiency. This case demonstrated the reversal of both pancytopenia and GMT following a course of corticosteroid and thyroid hormone replacement therapy.

It is possible that our patient's GMT was partly caused by cachexia due to the effects of his oral cancer. Both the pancytopenia and GMT were reversed with hormone replacement therapy alone, but his poor nutritional status was also partly improved following the resolution of several metabolic abnormalities. Therefore, it cannot be ruled out that the improvement of his nutritional status could have also contributed to the reversal of his GMT.

It is also possible that regardless of the treatment of his adrenal insufficiency, the GMT could have been reversed by the glucocorticoid therapy which was administered in tandem with the steps taken to improve his nutritional status. In addition, the markedly increased cortisol levels that were observed after an intramuscular administration of longacting ACTH at a dosage of $1 \mathrm{mg} / \mathrm{day}$ for 4 days could have demonstrated a pharmacological effect for the resolution of his GMT. However, there have been no previous reports of the reversal of GMT through glucocorticoid therapy alone.

The patient was diagnosed with an idiopathic primary ad- 
renal insufficiency of an unknown etiology. There have been no reports of an adrenal insufficiency caused by either cachexia or a poor nutritional status. It is also unlikely that his adrenal insufficiency was caused by a metastasis of his oral cancer because there were no morphological abnormalities noted in his adrenal glands. It is possible that his primary adrenal insufficiency could have been caused by autoimmune adrenalitis; however, the findings of an antiadrenocortical antibody assay were negative.

The patient's serum cortisol level showed a partial response to a rapid ACTH test and his urinary excretion of free cortisol was adequately increased after the administration of ACTH at a dosage of $1 \mathrm{mg} /$ day for 4 days. The cortisol response to the ACTH depends on the degree of adrenal failure, and some patients with partial or mild primary adrenal insufficiency may have borderline or normal ACTH stimulation test results. A diagnosis of adrenal insufficiency should, therefore, not be based on the ACTH stimulation test results alone, but also on such clinical evidence as a serum electrolyte imbalance or an elevation of the plasma ACTH level. In our patient, the plasma ACTH level remained high after repeated measurements, and his low blood pressure, hyponatremia and hypoglycemia were consistent with an adrenal insufficiency. He was therefore diagnosed with a partial primary adrenal insufficiency.

Several factors could have contributed to the development of both hyponatremia and hypoglycemia despite an existing partial adrenal insufficiency. One factor could be that his glucocorticoid requirement was relatively high because of his cachexia from the oral cancer. The thyroid hormone replacement therapy could have also increased his glucocorticoid requirements by stimulating his metabolism; however, in this case, the replacement dose prior to his admission was insufficient to cause this effect. The chronic administration of antiepileptic agents such as phenytoin could cause hepatic microsomal enzyme induction, thereby increasing the clearance rate of cortisol $(15,16)$. A glucocorticoid deficiency has reportedly been developed following the initiation of phenytoin treatment in a patient with primary adrenal insufficiency (17). It would be preferable to use a different antiepileptic drug which would not affect the hepatic clearance of synthetic steroids, but our patient required the continuation of his phenytoin treatment for seizure control.

The mechanisms causing GMT in patients with an adrenal insufficiency or hypothyroidism are unclear. The gelatinous material that forms in the bone marrow is histologically analogous to the mucopolysaccharide deposition that is characteristic of myxedema. This similarity may explain the association between GMT and hypothyroidism. The wide range of diseases associated with GMT suggests that the gelatinous change may result from changes to an unknown yet common bioregulatory pathway that is activated by these various pathological conditions. Another possibility is that many different bioregulatory pathways may lead to morphologically similar changes in the bone marrow. Interestingly, it has been reported that the total white cell count, the he- moglobin level and the platelet count did not correlate with the degree of GMT (3). A number of patients with metabolic disorders may have GMT, especially patients with mild cytopenia, but this is not detected unless a bone marrow biopsy is performed. However, an examination of the bone marrow is not frequently performed in patients with metabolic disorders such as an adrenal insufficiency or hypothyroidism. An evaluation of a larger number of cases is needed in order to further evaluate the associations between metabolic disorders and GMT. This expanded evaluation could contribute to an increased understanding of the mechanisms that cause GMT, as well as a more complete picture of the roles of steroid and thyroid hormones in hematopoiesis.

In conclusion, we herein presented the findings of a rare case of a primary insufficiency of the adrenal and thyroid glands associated with GMT, which was successfully resolved through the use of corticosteroids and thyroid hormone replacement therapy.

The authors state that they have no Conflict of Interest (COI).

\section{References}

1. Michael P. Gelatinous degeneration of the bone marrow. J Pathol 33: 533-538, 1930.

2. Clarke BE, Brown DJ, Xipell JM. Gelatinous transformation of bone marrow. Pathology 15: 85-88, 1983.

3. Bohm J. Gelatinous transformation of the bone marrow: the spectrum of underlying diseases. Am J Surg Pathol 24: 56-65, 2000.

4. Mant MJ, Faragher BS. The haematology of anorexia nervosa. BrJ Haematol 23: 737-749, 1972.

5. Nonaka D, Tanaka M, Takaki K, Umeno M, Okamura T, Taketa H. Gelatinous bone marrow transformation complicated by selfinduced malnutrition. Acta Haematol 100: 88-90, 1998.

6. Tavassoli M, Eastlund DT, Yam LT, Neiman RS, Finkel H. Gelatinous transformation of bone marrow in prolonged self-induced starvation. Scand J Haematol 16: 311-319, 1976.

7. Ifrah N, Saint Andre JP, De Gentile L, et al. Gelatinous transformation of the bone marrow: Manifestation of an acute leukemia? Acta Haematol 82: 165-168, 1989.

8. Feng CS. Gelatinous transformation of marrow in a case of acute myelogenous leukemia post chemotherapy. Am J Haematol 38: 220-222, 1991.

9. $\mathrm{Ng} \mathrm{MH,} \mathrm{Li} \mathrm{EK,} \mathrm{Feng} \mathrm{CS.} \mathrm{Gelatinous} \mathrm{transformation} \mathrm{of} \mathrm{bone} \mathrm{mar-}$ row in systemic lupus erythematosus. J Rheumatol 16: 989-992, 1989.

10. Marche C, Tabbara W, Michon C, Clair B, Bricaire F, Matthiessen L. Bone marrow findings in HIV infection. A pathological study. Prog AIDS Pathol 2: 51-60, 1990.

11. Mehta K, Gascon P, Robboy S. The gelatinous bone marrow (serous atrophy) in patients with acquired immunodeficiency syndrome. Evidence of excess sulfated glycosaminoglycan. Arch Pathol Lab Med 116: 504-508, 1992.

12. Seaman JP, Kjeldsberg CR, Linker A. Gelatinous transformation of the bone marrow. Hum Pathol 9: 685-692, 1978.

13. Sen R, Singh S, Singh H, Gupta A, Sen J. Clinical profile in gelatinous bone marrow transformation. J Assoc Physicians India 51: 585-588, 2003.

14. Savage RA, Slipple C. Marrow myxedema. Gelatinous transformation of marrow ground substance in a patient with severe hypothyroidism. Arch Pathol Lab Med 111: 375-377, 1987. 
Intern Med 52: 1931-1936, 2013 DOI: 10.2169/internalmedicine.52.0081

15. Choi Y, Thraser K, Werk EE, Sholiton LJ, Olinger C. Effect of diphenylhidantion on cortisol kinetics in humans. J Pharmac Exp Ther 176: 27-34, 1971.

16. Putignano $P$, Kaltsas GA, Satta MA, Grossman AB. The effects of anti-convulsant drugs on adrenal function. Horm Metab Res 30:
389-397, 1998.

17. Kara C, Ucakturk A, Aydin OF, Aydin M. Adverse effect of phenytoin on glucocorticoid replacement in a child with adrenal insufficiency. J Pediatr Endocrinol Metab 23: 963-966, 2010.

(C) 2013 The Japanese Society of Internal Medicine http://www.naika.or.jp/imonline/index.html 